\title{
Major limb amputations in a tertiary hospital in North Western Nigeria.
}

\author{
Chikwendu Nwosu ${ }^{1}$, Misbau O Babalola ${ }^{2}$, Muhammad H Ibrahim ${ }^{1}$, Siyaka I Suleiman ${ }^{1}$
}

Departments of Surgery,

1. Federal Medical Centre, Birnin Kebbi, Kebbi State,

2. University of Ilorin Teaching Hospital, Ilorin, Kwara State, Nigeria

\begin{abstract}
Background: Amputation is the removal of whole or part of a limb, often as a life saving measure. It is a mutilating surgical procedure altering the body image and producing severe functional deficit. It is a common orthopedic surgical procedure performed worldwide.

Aims and objectives: The aim of this study was to determine the pattern and indications for amputation in Federal Medical Centre, Birnin Kebbi, Kebbi State, Nigeria; between January 2008 and December 2014, in a bid to proffer preventive measures. Patients and methods: This was a retrospective study of consecutive patients who had major limb amputations at the Federal Medical Centre, Birnin Kebbi, Kebbi State, Nigeria; between January 2008 and December 2014. Case notes of patients were retrieved with relevant information extracted and analyzed.

Results: A total of 112 amputations were studied. The age range of patients was between 3-89 years. Amputation in 23.5\% of patients was due to trauma, followed by diabetic foot gangrene in $21 \%$ of cases. About $42.9 \%$ of the amputations were above knee, followed by below knee amputations in $37 \%$ of cases. The lower limbs were involved in $84.8 \%$ of cases and upper limbs in $15.2 \%$ of cases.
\end{abstract}

Conclusion: Trauma was the most predominant indication for amputation in this study. This was followed by diabetic foot gangrene. This is usually due to the high rate of road traffic accidents and consequent mismanagement by traditional bone setters.

Keywords: Limb amputations, tertiary hospital, North Western Nigeria.

DOI: https://dx.doi.org/10.4314/ahs.v17i2.26

Cite as: Nwosu C, Babalola MO, Ibrabim MH, Suleiman SI. Major limb amputations in a tertiary hospital in North Western Nigeria. Afri Health Sci. 2017;17(2): 508-512. bttps:// dx.doi.org/10.4314/abs.v17i2.26

\section{Introduction}

Amputation is the surgical removal of an external part of the body, most often a limb or part of it as a form of treatment. ${ }^{1}$ A major amputation is one that is performed proximal to the ankle or wrist. ${ }^{2}$ The sudden and unexpected loss of the extremity to trauma (without going through a pre-loss adaptation) is a devastating condition. ${ }^{3}$ The indications for amputation are trauma, malignant tumors, diabetic gangrene, peripheral artery disease, limb infections and burns. ${ }^{4}$
Corresponding author:
Chikwendu Nwosu,
Department of Surgery,
Federal Medical Centre,
Birnin Kebbi,
Kebbi State, Nigeria.
Tel: +2348063115284
Email: nwosuchikwe@yahoo.co.uk

While the indications for amputation in Europe and America are dwindling, the situation in Nigeria is worsening, as many treatable cases end up in amputation. ${ }^{5} \mathrm{Ni}$ geria also suffers from the lack of adequate rehabilitation for these unfortunate patients who as a result end up on the streets as glorified beggars. ${ }^{5}$ The most common indication for amputation in Nigeria is trauma, while in the U.S.A, it is peripheral vascular disease. Other indications include diabetic foot gangrene, infections, neoplasm, gunshot injuries and congenital deformities. ${ }^{6}$ However the trend is said to be changing in favor of diabetic foot gangrene, according to recent literature from various regions. ${ }^{2,7,8,9,11}$ Unfortunately patients in developing countries often present late, when limb salvage is not a viable option. ${ }^{8}$

Limb amputation is not only a loss of physical integrity, but it also affects individuals' mental and social well being. ${ }^{9}$ It is a significant problem especially for the youth and working population. ${ }^{9}$ In spite of the latest improvements in adapting to amputation and invention of im- 
proved prosthesis, surgeons consider it as the last treatment option. ${ }^{10}$ Medico-legal issues sometimes influence decision making with regard to salvaging or amputating a limb. The decision to perform limb salvage or primary amputation is thus a crucial one for the surgeon to make, and it is imperative that the surgeon makes a good initial decision. ${ }^{11}$

In Nigeria, most of the limb amputations are preventable through public enlightenment, good health care policies, and the provision of affordable appropriate health care that the patient could access on time. ${ }^{12}$ Controversies exist on the highest indication for major limb amputations in Nigeria. ${ }^{7}$ Ours is the first research on epidemiology in Kebbi State, North Western Nigeria. The aim of this study was to determine the pattern and indications for amputation in our environment and to make necessary recommendations towards their prevention.

\section{Patients and methods}

This was a retrospective study of major limb amputa- tions performed in Federal Medical Centre, Birnin kebbi, North Western Nigeria, from January 2008 to December 2014. Data was collected on age, gender, indication, limb affected and level of amputation. Only case notes of patients who had complete medical records were included in this study. Data collected was analyzed using the Statistical Package for Social Sciences for Windows version 17.0 (SPSS Inc. Chicago Illinois). Results are presented with descriptive statistics.

\section{Results}

A total of 116 amputations were performed in $117 \mathrm{pa}-$ tients. One patient had bilateral below knee amputation. Four case files were excluded from the study due to incomplete records. A total of 112 amputations were studied. $77(68.1 \%)$ were males while $35(31.9 \%)$ were females. The male-female ratio was 2.1:1. The age range was from 3-89 years $($ mean=32.4). The peak age group was 0-16 years (Table 1$)$.

\begin{tabular}{|ccc|}
\hline Table 1 - Age distribution (Years) & \\
& Frequency & Percent \\
$0-16$ & 22 & 19.6 \\
$17-25$ & 21 & 18.8 \\
$26-35$ & 16 & 14.3 \\
$36-45$ & 14 & 12.5 \\
$46-55$ & 12 & 10.7 \\
$56-65$ & 12 & 10.7 \\
$66+$ & 15 & 13.4 \\
Total & 112 & 100.0 \\
\hline
\end{tabular}

$41.7 \%$ of upper limb amputations occurred in children. Of the amputations in children, 18(79.2\%) were due to trauma of which $14(62.5 \%)$ resulted from poor management.

(Table 4) Out of 90 amputations performed in adults, 26 $(30.5 \%)$ were due to trauma, $25(26.3 \%)$ were due to di- abetic foot gangrene, $19(22.1 \%)$ were due to neoplasm, $13(13.7 \%)$ were due to peripheral vascular disease and 7 $(7.4 \%)$ due to post-infective gangrene.

$27(24.1 \%)$ amputations were due to trauma, followed by diabetic foot gangrene which is $26(23.2 \%$ ) (Table 2$)$. $98(84.8 \%)$ amputations were in the lower limb while $17(15.2 \%)$ were in the upper limb (Table 3$)$. 


\begin{tabular}{|c|c|c|c|}
\hline \multicolumn{4}{|c|}{ Table 2 - Indications for amputation } \\
\hline & Frequency & Percent \\
\hline \multicolumn{2}{|l|}{ Diabetic foot } & 26 & 23.2 \\
\hline \multicolumn{2}{|c|}{ Post traumatic gangrene } & 27 & 24.1 \\
\hline \multicolumn{2}{|c|}{ Neoplasia } & 22 & 19.6 \\
\hline \multicolumn{2}{|c|}{ Sequel of tradition bone setter } & 18 & 16.1 \\
\hline \multicolumn{2}{|c|}{ Post infective gangrene } & 10 & 8.9 \\
\hline \multicolumn{2}{|c|}{ Peripheral vascular disease } & 9 & 8.0 \\
\hline \multicolumn{2}{|c|}{ Total } & 112 & 100.0 \\
\hline \multicolumn{4}{|c|}{ Table 3 - Type of amputation } \\
\hline \multicolumn{2}{|l|}{ Frequency } & \multicolumn{2}{|l|}{ Percent } \\
\hline Above knee & 51 & 45.5 & \\
\hline Below knee & 44 & 39.3 & \\
\hline Above elbow & 15 & 13.4 & \\
\hline Below elbow & 2 & 1.8 & \\
\hline Total & 112 & 100.0 & \\
\hline
\end{tabular}

Of the upper limb amputations, $45.5 \%$ occurred in chil- dren. (Table 4 ). In diabetic foot disease, 56\% had below knee amputation; while $44 \%$ had above knee amputation.

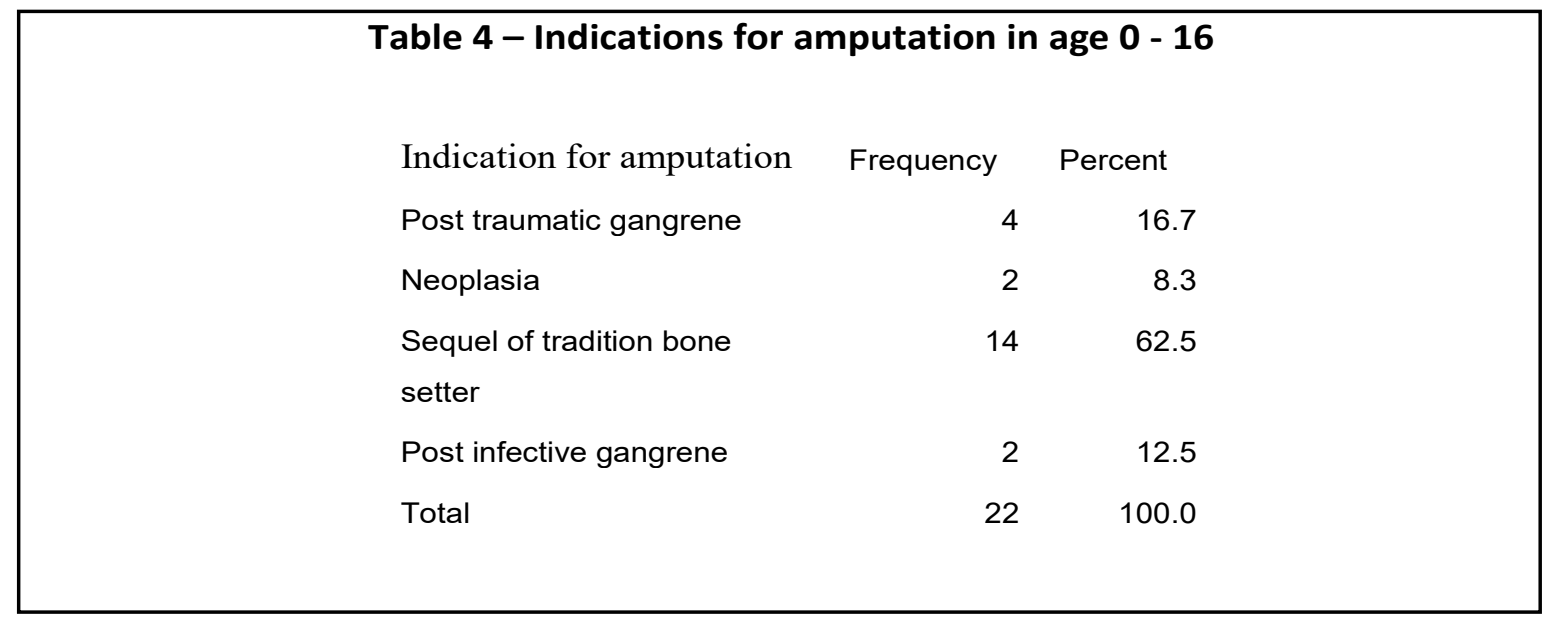

\section{Discussion}

The study showed a male preponderance. This study is in keeping with the findings of other studies, where there was a male preponderance..$^{2,3,8,10,13}$ However the ratio varied from one region to another. ${ }^{12}$ This is similar to the findings of Ofiaeli in SouthEast Nigeria ${ }^{13}$ and Dada and Awoyomi in SouthWest Nigeria. ${ }^{7}$ This is probably due to the fact that males are more involved in trauma, being more active.
Amputations in the pediatric age group occur usually as a result of poor management of trauma. Parents should take better care of their children as well as present early to hospital in case of trauma. The active age group of $17-$ 49 years accounted for majority of the amputations. Most of these patients are young adult males in the productive age group. Amputations in this age group result in serious economic crisis for the family especially where prosthetic 
use is poor. ${ }^{14}$ This is similar to the findings of Kidmas et al. ${ }^{14}$ and Ajibade et al. ${ }^{3}$

Trauma is the commonest indication for amputation, followed by diabetic foot gangrene. This is similar to the findings of studies conducted in various regions of Africa. ${ }^{2,3,8,10,12,13,14,15}$

In a study conducted by Dada et al. $^{7}$ diabetic foot disease is the most common indication. In children, trauma is the most common indication for amputation, as a direct result of poor management. This agrees with the findings of Akinyoola AL et al. ${ }^{16}$ and Yakubu A et al. ${ }^{17}$ This very high number of limb amputations in children is certainly preventable by early and effective management of fractures.

Above knee amputations accounted for majority of the amputations followed by below knee amputations. This agrees with the findings of Umaru et al. $^{7}$ and Kidmas et al. ${ }^{12}$ However it contrasts with the findings of Odatuwa-Omagbemi and Dada et al. ${ }^{14,18}$ It is also different from the findings of studies conducted in the developed countries. ${ }^{19}$ In diabetic foot disease, more below knee amputations were performed than above knee amputations. The higher rate of below knee amputations was an indication of early presentation and increased awareness of the disease. The prevalence of diabetes mellitus in Fulani ethnic group in NorthWestern Nigeria who have settled in an urban environment is higher than the same ethnic group in rural settings. ${ }^{20}$ The lower rate among the rural dwellers can be attributed to a more traditional lifestyle which depends on animal husbandry and subsistence economy. ${ }^{20}$ Most lower limb amputations in patients with diabetes are preceded by a foot ulcer, whose risk factors apart from peripheral vascular disease and peripheral neuropathy, are barefoot walking, inappropriate footwear, poor foot hygiene and delay in seeking medical attention. ${ }^{21}$ These non-traditional risk factors can be modified if identified early, and if patients have adequate knowledge of foot care and put that knowledge into practice. ${ }^{22}$

Lower limb amputations were performed more than upper limb amputations. This is probably due to the fact that the lower limb is more involved in trauma, complications of diabetes mellitus and peripheral vascular disease.

The rate of major limb amputations is high in our environment, with physical, emotional, economic and psychological impairment. Trauma mostly results from road traffic accidents, assaults and falls from heights. ${ }^{2}$ Drivers should be educated on road traffic rules. Roads should be properly maintained and legislation on speed limit enforced. Traditional bone setters' practice should be regulated by the government. They should be taught basic principles of fracture care. They should know when to refer a patient to the hospital. ${ }^{18}$ The need for regular medical checkup should be re-emphasized. This will enable the early detection of diseases such as diabetes mellitus, so as to commence early treatment and reduce complications. Hospitals and government should organize regular health seminars with the aim of reducing conditions that will lead to amputations.

Patients that had amputations should be counselled on the need for prostheses afterwards to ensure proper rehabilitation and productivity. Ideally, such rehabilitation should begin from the moment the decision to amputate is made and requires a multidisciplinary approach involving the surgeon, prosthetist, physiotherapist, occupational therapist and social worker. ${ }^{23}$

\section{Conclusion}

Trauma is the predominant cause of limb amputations. This is followed by diabetic foot gangrene. Amputation is performed more in the lower limb than the upper limb. More amputations are performed in the productive age group. Concerted efforts are needed towards reducing the rate of amputation.

\section{Conflict of interest}

We have no conflict of interest to declare.

\section{References}

1. Udosen AM, Ngim N, Etokidem A, Ikpeme A, Urom S, Marwa A. Attitude and perception of patients towards amputation as a form of surgical treatment in the University of Calabar Teaching Hospital, Nigeria. Afr Health Sci. 2009; 9(4):254-257. PubMed

2. Ajibade A Akinniyi OT, Okoye CS. Indications and complications of major limb amputations in Kano, Nigeria. Ghana Med J, 2013;47(4):185-188. PubMed

3. Omoke NI, Chukwu CO, Madubueze CC, Egwu AN. Traumatic extremity amputation in a Nigerian setting: Patterns and challenges of care. Int. Orthop. March 2012; 36(3):613-618. PubMed

4. Thanni LO, Tade AO. Extremity amputations in Nigeria - A review of indications and mortality. Surgeon 2007, Aug;5(4): 213-7

5. Yinusa W, Ugbeye ME. Problems of amputation 
surgery in a developing country Int. Orthop. (SICOT) 2003,27:121-124

6. Obalum DC, Okeke DC. Lower limb amputation at a Nigerian private tertiary hospital. West Afr J Med 2009, 28(1):24-26. PubMed

7. Dada AA, Awoyomi BO. Is the trend of amputation in Nigeria changing? A review of 51 consecutive cases seen at Federal Medical Centre, Ebutte Metta, Nigeria. Niger J. Med. 2010,51:167-169

8. Chalya PL, Mabula PJ, Dass RM, Ngayomela IH, Chandika $\mathrm{AB}$, Mbelenge $\mathrm{N}$, et al. Major limb amputations, $\mathrm{A}$ tertiary hospital experience in North Western Tanzania. $J$ Orthop Surg Res 2012;7:18

9. Kauzlaric N, Kauzlaric KS, Kolundzic R. Prosthetic rehabilitation of persons with lower limb amputations due to tumor. Eur J Cancer Care 2007;16(3):238-48. PubMed

10. Alireza R, Mohajerzadeh S. An epidemiological and etiological report on lower limb amputation in North Western Iran. Arch Bone Jt Surg Dec. 2013;(12):103-106 11. Olutola A, Shonubi AM, Musa A, Sule G. Major limb amputations: An audit of indications in a suburban surgical practice. J National Med Asso 2005;97(1):74-78. PubMed

12. Odatuwa-Omagbemi D, Adiki O. Extremity amputations in Warri, South-South Nigeria. J West Afr Coll Surg. 2012, Jan-Mar;2(1):14-24

13. Ofiaeli RO. Indications, Levels and Outcome of lower extremity amputations in Nnewi Nigeria. JOMIP. 2001:2(5):18-21

14. Kidmas AT, Nwadiaro CH, Igun GO. Lower limb amputations in Jos, Nigeria. East AfrMed J 2004;81(8):427429. PubMed
15. Ogengo JA, Obimbo MM, Kingori J. Pattern of limb amputation in a Kenyan rural hospital. Int Orthop. Oct. 2009;33(5):1449-1453. PubMed

16. Akinyoola AL, Oginni LM, Adegbehingbe OO, Orimolade EA, Ogundele OJ. Causes of limb amputations in Nigerian Children. West Afr J Med. 2006 OctDec;25(4):273-275

17. Yakubu A, Muhammad I, Mabogunje O. Limb amputation in children in Zaria, Nigeria. Ann. Trop. Paediatrics 1995 Jun; 16(2):163-165

18. Umaru RH, Gali BM, Ali N. The role of inappropriate traditional splintage in limb amputation in Maiduguri, Nigeria. Annals of Afr Med. 2004;3(3):138-140. PubMed 19. Swaminathan A, Vemulapalli S, Jones WS. Lower extremity amputation in peripheral artery disease: Improving patient outcome. Vasc. Health risk Manag. 2014;10:41742. PubMed

20. Sabir A, Ohwovoriole A, Isezuo S, Fasanmade O, Abubakar S, Iwuala S. Type 2 diabetes mellitus and its risk factors among Northern Fulani of Northern Nigeria. Ann Afr Med 2013;12(4):217-222. PubMed

21. Abbas ZG, Archibald LK. Challenges for management of the diabetic foot in Africa: doing more with less. Int Wound J. 2007 Dec; 4(4):305-13.

22. Faraja SC, Marina AN. Diabetic foot: prevalence, knowledge, and foot self-care practices among diabetic patients in Dar es Salaam, Tanzania - a cross-sectional study. J Foot Ankle Res. 2015; 8: 20.

23. Ogeng'o JA, Obimbo MM, King'ori J. Pattern of limb amputation in a Kenyan rural hospital. International Orthopaedics. 2009;33(5):1449-1453. 